\title{
The Association between Degenerative Spine Disease and Obesity in Cancer Patients: An Evaluation by Bone Scintigraphy
}

\author{
Ahmed A. Kandeel 1, Rehab Abdel Meguid 1, Ahmed Nasr ${ }^{2}$, Medhat Abdel Samiea ${ }^{2}$, \\ Khalid F. Kassem ${ }^{3}$
}

${ }^{1}$ Nuclear Medicine Department, Kasr Al-Ainy Center of Clinical Oncology \& Nuclear Medicine, Kasr Al-Ainy School of Medicine, Cairo University, Cairo, Egypt; ${ }^{2}$ Nuclear Medicine Department, Maadi Armed Forces Medical Compound, Cairo, Egypt; ${ }^{3}$ Internal Medicine Department, Kasr Al-Ainy School of Medicine, Cairo University, Cairo, Egypt

Background: Degenerative changes of the spine are common in obese cancer patients and are frequently confusing during the interpretation of bone scan of those patients.

Aim: To investigate the influence of body weight on the frequency of degenerative spine disease in a cohort of cancer patients using technetium-99m methylene diphosphonate (Tc-99m MDP) bone scan.

Methods: A prospective study of 100 cancer patients with or without back pain referred for bone scanning. Their mean age was $58.5 \pm 10.2$ years and $46 \%$ were males. Tc-99m MDP bone scan was done followed by spinal magnetic resonance imaging (MRI) examination. Patients were divided into two groups according to the body mass index (BMI) into group 1 including 60 overweight and obese $(\mathrm{BMI} \geq 25)$ patients and group 2 including 40 non-obese $(\mathrm{BMI}<25)$ patients serving as a control group. Any spot of enhanced radiotracer uptake at any part of the vertebrae was considered abnormal and correlated with MRI findings.

Results: A total of 168 vertebral lesions were detected by bone scan (150 in group 1 and 18 in group 2) with significant difference between both groups and between different grades of obesity in group 1. All lesions were accurately localized and proved to be of degenerative nature by MRI. The percentage of patients with back pain in group 1 was significantly higher than in group 2 (65\% vs. $35 \%$, respectively).

Conclusion: Bone scintigraphy is a good technique to detect degenerative spinal disease in obese cancer patients.

Keywords: Degenerative spine disease, Bone scan, Obesity, Cancer

Corresponding Author: Ahmed A. Kandeel, M.D; Nuclear Medicine Department, Kasr Al-Ainy Center of Clinical Oncology \& Nuclear Medicine, Kasr Alainy School of Medicine, Cairo University, Cairo, Egypt; E-mail:

ahmedkandeel@yahoo.com

Submitted: 8-October-2017, Revised: 25-October-2017, Accepted: 28-October-2017, Published online: 21-November-2017

\section{INRTODUCTION}

Spinal degeneration involves anatomical changes in the disc, osseous structure, ligaments, and articular cartilage of the facet joints. There is, however, an interrelationship of the different components of the spine in these changes in one component, such as the disc and the viability of the chondrocytes ${ }^{1}$.

In developed countries, an estimated $40 \%$ to $70 \%$ of adults having suffered low back pain with loss of working time ${ }^{2}$. Obesity increases the risk of low back pain and radicular pain ${ }^{3,4}$.

Patients with primary malignancy known to metastasize to bone are usually referred to perform bone scanning as a part of routine metastatic work up or during regular follow up if there are newly developed bony aches especially the spine suspected to be of metastatic origin.

Technetium labeled phosphate complexes injected intravenously are suggested to be absorbed by chemical bonding at dislocation sites on the surface of hydroxyapatite with release of tinamol Tc-99m which are hydrolyzed and bound to bone either separately or together as hydrated tin oxide and technetium dioxide. The large surfaces available for exchange by chemical absorption of technetium tin phosphate complex at growth centers and reactive bone lesions results in high concentrations of radiopharmaceutical at such sites ${ }^{5}$.

The aim of this work was to investigate the influence of patient's body weight on the incidence of degenerative spine disease in a cohorot of cancer patients using technetium-99m methylene diphosphonate (Tc-99m MDP) bone scan.

\section{METHODS}

This prospective study included 100 cancer patients referred to Maadi Armed Forces Medical Compound during 6-month duration to perform bone scanning for metastatic work up or due to presence of bone complaint especially back pain. The local ethics committee gave approval for the study. Patient's consents were taken to perform complementary magnetic resonance imaging (MRI) examination of the spine. 
Exclusion criteria included patients with low BMI $(<20)$, known metastases in the spine and previous spinal radiotherapy, surgery, fracture or trauma.

All patients were subjected to clinical history and examination for presence or absence of back pain. Body mass index (BMI) was calculated according to the following equation: $\mathrm{BMI}=$ weigh $(\mathrm{kg})$ divided by square meter of height $\left(\mathrm{m}^{2}\right)$ (The Quetelet Index) ${ }^{6}$. Grade of obesity was determined according to different values of BMI as seen in table 1 .

Table 1. Grading of obesity according to body mass index

\begin{tabular}{lll}
\hline Grade of obesity & Body mass index & Score \\
\hline Underweight & $<18.5$ & \\
\hline Healthy & $18.5-24.9$ & $\mathrm{H}$ \\
\hline Overweight & $25-29.9$ & 0 \\
\hline Grade 1 obesity & $30-34.9$ & 1 \\
\hline Grade 2 obesity & $35-39.9$ & 2 \\
\hline Grade 3 morbid obesity & $\geq 40$ & 3 \\
\hline
\end{tabular}

Conventional Tc-99m MDP bone scan was done followed within 1-7 days by MRI examination of the part of the spine suspicious for the presence of vertebral degenerative lesions on bone scanning. Bone scanning was interpreted by two experienced nuclear medicine physicians who examined the studies independently while blinded to the clinical or other radiological data. Patients were allocated according to BMI into two groups: group 1 included 60 overweight and obese patients with a BMI $\geq 25$ and group 2, the control group, included 40 non-obese patients with a BMI $<25$.

\section{Radiopharmaceuticals used and imaging protocol}

Intravenous injection of $20 \mathrm{mCi}(740 \mathrm{MBq}) \mathrm{Tc}-99 \mathrm{~m}$ MDP adult dose was given via a cannula. Site of injection was selected to avoid known or suspected pathological conditions. Imaging was done using a large field-of-view dual head, gamma camera equipped with a low-energy, high-resolution, parallel-hole collimator and peaked at $140 \mathrm{keV}$ with a symmetric $20 \%$ window and zoom 1.

All patients were instructed to hydrate properly following tracer injection by drinking at least 1.5 liters of fluids. Patients returned 2-4 hours later for delayed images and voided immediately before scanning. All metal objects were removed. Anterior and posterior whole body views of the entire skeleton were taken and if needed, planar static images of the spine were taken.

\section{Image interpretation}

Any spot of enhanced radiotracer uptake at any part of the vertebrae was considered abnormal and correlated with MRI findings.

\section{Statistical analysis}

The statistical analysis was done using the Statistical Package for the Social Science (SPSS Inc., Chicago, IL, USA) version 18 for Microsoft Windows. Data were statistically described in mean \pm standard deviation $( \pm \mathrm{SD})$, median and range, or frequencies and percentages when appropriate. Comparison of numerical variables between the study groups was done using Student $t$ test for independent samples. For comparing categorical data, Chi square $\left(\chi^{2}\right)$ test was performed. Pearson rank correlation equation was used to correlate quantitative data. $\mathrm{P}<0.05$ was considered significant.

\section{RESULTS}

Characteristics of the study population are shown in table 2. Age of patients ranged between 30 and 78 years with a mean of $58.5 \pm 10.2$. More than half $(54 \%)$ of patients were females and breast cancer was the commonest primary cancer in both groups followed by prostate cancer.

In groups 1 and 2, the patients were matched in their age and height. Females were more prevalent in the obese group. Obese patients in group 1 had a significant higher weight and BMI when compared with non-obese patients in group $2(\mathrm{p}<0.001)$ (table 2$)$

Table 2. Demographic and clinical characters of patients

\begin{tabular}{llll}
\hline & $\begin{array}{l}\text { Group 1 } \\
\text { (obese } \\
\text { patients) }\end{array}$ & $\begin{array}{l}\text { Group 2 } \\
\text { (non-obese } \\
\text { control) }\end{array}$ & Total \\
\hline No. & 60 & 40 & 100 \\
\hline Age (years) & & & \\
\hline Mean \pm SD & $58.3 \pm 9.9$ & $59.3 \pm 11.3$ & $58.5 \pm 10.2$ \\
Sex & & & \\
\hline Female & $36(60 \%)$ & $18(45 \%)$ & $64(64 \%)$ \\
\hline Male & $24(40 \%)$ & $22(55 \%)$ & $46(46 \%)$ \\
\hline 1ry cancer & & & $32(32 \%)$ \\
\hline Breast & $20(33 \%)$ & $12(30 \%)$ & $24(24 \%)$ \\
\hline Prostate & $14(23 \%)$ & $10(25 \%)$ & $18(18 \%)$ \\
\hline Lung & $10(17 \%)$ & $8(20 \%)$ & $16(16 \%)$ \\
\hline Colorectal & $10(17 \%)$ & $6(15 \%)$ & $10(10 \%)$ \\
\hline Bladder & $6(10 \%)$ & $4(10 \%)$ & $103.7 \pm 20.7$ \\
\hline Weight $(\mathrm{kg}) *$ & & & \\
\hline Mean \pm SD & $113 \pm 14.1$ & $75.9 \pm 9.5$ & \\
\hline Height $(\mathrm{cm})$ & & $1.7 \pm 0.1$ & $1.6 \pm 0.1$ \\
\hline Mean \pm SD & $1.6 \pm 0.1$ & & \\
\hline$* p<0.001$ & & & \\
\hline
\end{tabular}

A total of 168 vertebral lesions were detected by bone scan in all patients (150 lesions in group 1 and 18 lesions in group 2).

The total number of vertebral lesions was 15 in grade 1 obesity patients, 21 in grade 2 and 114 in grade 3. A statistically significant difference was elicited between both groups as well as between different grades of obesity in group 1 ( $p<0.05$, table 3$)$.

On bone scan, all 60 patients in group 1 showed more than 1 vertebral lesions being 2 lesions in half of patients and 3 lesions in the other half. On the other hand, the majority $(60 \%)$ of non-obese patients were free 


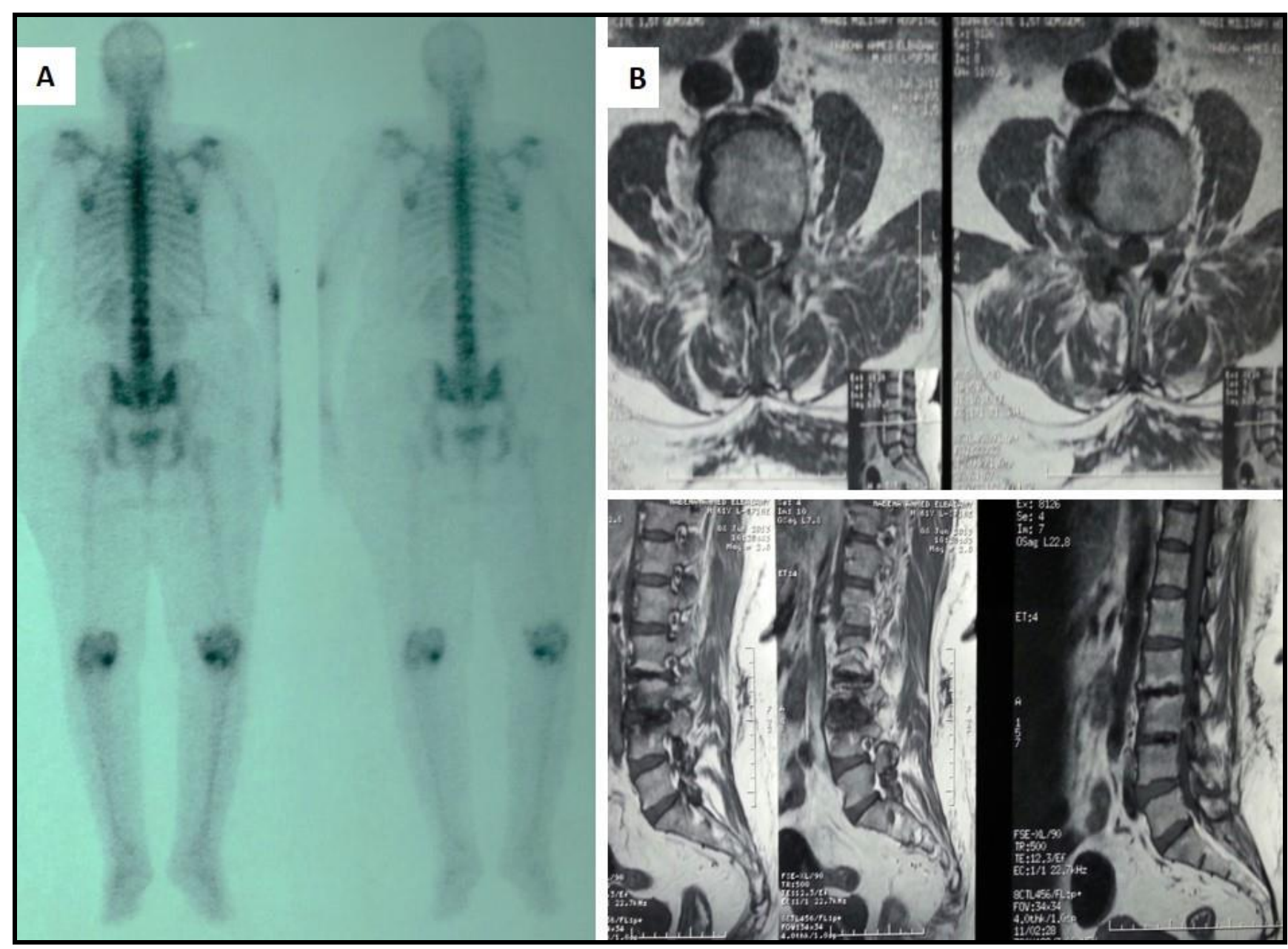

Figure 1: 61 years old female with breast cancer, low back pain and a body mass index of 46. A: Bone scan showing enhanced tracer uptake in the mid and lower lumbar vertebra interpreted as degenerative changes. B: MRI confirmed these findings by showing spondylo-degenerative changes at L3-L4, L4-L5 lumbar vertebra with diffuse disc bulge at L3-L4 and L4-L5.

on bone scan, $35 \%$ had one lesion detected and only 2 patients $(5 \%)$ had 2 lesions. Vertebral degenerative lesions were mainly lumbar in all positive cases.

All lesions were accurately localized and proved to be of degenerative nature by MRI (figure 1).

Table 3. Number of vertebral lesions detected by bone scan and back pain among obese and non-obese patients

\begin{tabular}{|c|c|c|c|}
\hline & $\begin{array}{l}\text { Group 1 } \\
\text { (obese } \\
\text { patients, } \\
\text { n=60) }\end{array}$ & $\begin{array}{l}\text { Group 2 } \\
\text { (non-obese } \\
\text { patients, } \\
\text { n=40) }\end{array}$ & $\begin{array}{l}\mathbf{p} \\
\text { value }\end{array}$ \\
\hline \multicolumn{4}{|c|}{$\begin{array}{l}\text { Number of vertebral } \\
\text { lesions per patient }\end{array}$} \\
\hline 0 & 0 & $24(60 \%)$ & $<0.05$ \\
\hline 1 & 0 & $14(35 \%)$ & \\
\hline 2 & $30(50 \%)$ & $2(5 \%)$ & \\
\hline 3 & $30(50 \%)$ & 0 & \\
\hline \multicolumn{4}{|c|}{ Back pain } \\
\hline No & $21(35 \%)$ & $26(65 \%)$ & $<0.05$ \\
\hline Yes & $39(65 \%)$ & $14(35 \%)$ & \\
\hline
\end{tabular}

Sixty-five percent of overweight/obese patients reported the presence of low back pain at time of scanning compared to only $35 \%$ of non-obese patients.

In correlation analysis, BMI showed significant positive association with the number of vertebral lesions in group $1(\mathrm{r}=0.63, \mathrm{p}=0.03)$.

\section{DISCUSSION}

High BMI is usually associated with low back pain which decreases overall quality of life and increases health-care costs. Disc degeneration is more often present in overweight and obese adults in percentages higher than persons with normal BMI. Multiple disc lesions with increase number and severity of lesions in MRI are more evident with elevated BMI, including narrowing of the disc space ${ }^{7}$.

The frequency of degenerative changes in the current study was $100 \%$ in overweight/obese patients compared to only $40 \%$ in non-obese patients. All lesions (mainly lumbar) were confirmed by MRI imaging. This finding matches to a great extent the results of Samartzis et al who conducted a large study at the University of Hong Kong including 2,599 participants. They found that there was a significant association of the extent, 
severity of degenerative disc lesions and high-grade disc degeneration with narrowing of the disc space using MRI in obese individuals with elevated $\mathrm{BMI}^{8}$.

A higher prevalence of degenerative lesions detected by bone scan was significantly correlated with degree of obesity. In the current study, in the overweight/obese group of patients, 114 lesions were seen in those with grade 3 obesity while 15 and 21 lesions were detected in grade 1 and 2 obesity compared with only 18 lesions in non-obese group with normal BMI. The same finding was observed in a crosssectional analysis of 187 individuals carried out by Kalichman et al who found a higher frequency of facet joint osteoarthritis in obese individuals who underwent CT for spinal degenerative changes assessment ${ }^{9}$.

The severity of low back pain was not clinically assessed in our patients as we only reported the presence or absence of back pain at the time of bone scan. This complaint was taken seriously by the referring doctor based on the natural history of our population rather than increased body weight as all of them had primary malignancy with a known spreading ability to bone. Our data revealed that $65 \%$ of patients in group 1 complained of low back pain compared to $35 \%$ in group 2 . The cause of low back pain was attributed to the presence of degenerative lumbar changes highly suggested in bone scan pattern and evidenced in MRI. Similarly, Shiri et al concluded that the severity of degenerative changes in the disc would explain the increased incidence of prolonged and chronic low back pain in obesity ${ }^{3}$. The relation between increased BMI and presence of low back pain could be explained by the assumption that end-stage disc degeneration with disc space narrowing (Schneider man grade 3) is often linked with degenerative changes in the vertebral column in the form of canal stenosis and ligamentous thickening and altered lumbar kinematics that increase the risk of low back pain 10 .

\section{Conclusion}

Bone scintigraphy is a good technique to establish the prevalence of spinal degeneration in patients with increased BMI. Using sensitive bone scan techniques yield results comparable to that of MRI examination. However, further studies are needed to recommend bone scan as an independent investigational tool for asymptomatic oncologic patients during their regular follow-up to keep track of progression of the degenerative disease in obese individuals especially with introduction of new techniques such as SPECT/CT fused facility in modern gamma cameras.

\section{Conflict of interest}

None to declare

\section{REFERENCES}

1. Miller JA, Schmatz C, Schultz AB. Lumbar disc degeneration: correlation with age, sex, and spine level in 600 autopsy specimens. Spine (Phila Pa 1976). 1988; 13(2): 173-178.

2. Kelsey JL, White AA 3rd. Epidemiology and impact of low back pain. Spine (Phila Pa 1976). 1980; 5(2): 133142.

3. Shiri R, Karppinen J, Leino-Arjas P, Solovieva S, ViikariJuntura E. The association between obesity and low back pain: a meta-analysis. Am J Epidemiol. 2010; 171(2): 135-154.

4. Shiri R, Lallukka T, Karppinen J, Viikari-Juntura E. Obesity as a risk factor for sciatica: a metaanalysis. Am J Epidemiol. 2014; 179(8): 929-937.

5. Jones AG, Francis MD, Davis MA. Bone scanning, radionuclide reactions mechanism. Semin Nucl Med. 1976; 6(1): 3-18.

6. Keys A, Fidanza F, Karvonen MJ, Kimura N, Taylor HL. Indices of relative weight and obesity. J Chronic Dis. 1972; 25(6): 329-343.

7. Gaziano JM. Fifth phase of the epidemiologic transition: the age of obesity and inactivity. JAMA 2010; 303(3): 275-276.

8. Samartzis D, Karppinen J, Chan D, Luk KD, Cheung KM. The association of lumbar intervertebral disc degeneration on magnetic resonance imaging with body mass index in overweight and obese adults: a population-based study. Arthritis Rheum. 2012; 64(5): 1488-1496.

9. Kalichman L, Guermazi A, Li L, Hunter DJ. Association between age, sex, BMI and CT-evaluated spinal degeneration features. J Back Musculoskelet Rehabil. 2009; 22(4): 189-195.

10. de Schepper EI, Damen J, van Meurs JB, et al. The association between lumbar disc degeneration and low back pain: the influence of age, gender, and individual radiographic features. Spine (Phila Pa 1976). 2010; 35(5): 531-536. 